\title{
Herbal medicine: from the past to the future
}

\author{
Varro E Tyler \\ Purdue University, P.O. Box 2566, W. Lafayette, IN 47996-2566, USA
}

\begin{abstract}
A brief discussion of the history of the use of herbal medicines from prehistoric times to the mid-twentieth century precedes an explanation of why usage of such remedies in the United States declined in the 1940s but returned to popularity in the 1980s. The provisions of the Dietary Supplement Health and Education Act of 1994 are presented together with its perceived influence, both positive and negative, on the health of the American people. Possible futures of herbal medicines are considered. The negative viewpoint that they will ultimately be rejected is refuted, and the more optimistic prediction that herbs are ultimately destined to become a part of mainstream medicine is defended. Stumbling blocks to such acceptance are evaluated and methods of overcoming them suggested. The urgent need for the development of a sensible regulatory environment encouraging the approval of botanicals as drugs is emphasized. After predicting a bright future for rational phytomedicines, the author opines that many of them will eventually play significant roles in medicinal practice.
\end{abstract}

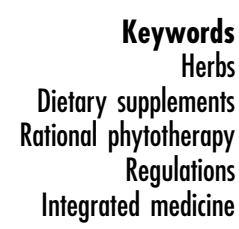

\section{History of herb use}

My title conveys significant meaning because to know the future you have to understand the past. The art of herbal medicine is extremely ancient, probably as old as humanity itself. In fact, it probably predates modern Homo sapiens. Archaeologists have found pollen and flower fragments from several different medicinal plants in Neanderthal tombs in Iraq dating back some 60,000 years. Species of Ephedra, Centaurea, Senecio, Althea and Achillea were among those identified ${ }^{1}$. This may attest to the common use of various herbal remedies at that very early date.

Cannabis ( $C$. sativa L.) is said to have been used in China for more than 8000 years $^{2}$. The poppy (Papaver somniferum L.) was initially cultivated in Mesopotamia about 5400 years ago $^{3}$, and the opium obtained from it has seen continuous medicinal use ever since. The mummified human discovered in the Italian Alps in 1991 and now referred to as the 'Iceman', possessed two pieces of birch fungus, Pitoporus betulinus (Bull.) Karst. Scientists speculate that this 5300-year-old human was using the fungus as a drug, possibly as a treatment for intestinal parasites ${ }^{4}$. The ancient origins of herbal medicine are indisputable.

The golden age of herbal medicine usage in the United States was probably the latter years of the 19th and the early years of the 20th centuries up to the passage of the Food and Drugs Act of 1906. Prior to this legislation, hundreds of proprietary herbal products, usually containing a high percentage of alcohol, were readily available on the American market. Some of them, such as Lydia E. Pinkham's Vegetable Compound ${ }^{5}$ and Swift's Syphilitic Specific, subsequently abbreviated to SSS Tonic ${ }^{6}$, continued to be marketed and are still remembered by many. However, the 1906 legislation sounded the death knell for most of these products and the outrageous advertising that promoted them.

\section{Rise and fall of botanical medicine in the United States}

The next 30 years continued to see the widespread use of botanical remedies, mostly in the form of concentrated extracts, fluidextracts, and tinctures. In fact, it could be said that such galenical preparations were the mainstays of medical practice during the period. Such products as Tincture of Digitalis U.S.P. and Fluidextract of Ergot U.S.P. were very widely used.

Initial curtailment of botanical remedies began in the mid-1930s with the introduction of sulfanilamide. This new German antibacterial drug stimulated synthetic organic chemists to produce thousands of new molecules with potential beneficial properties, and the race was on.

Introduction of new, often extremely useful, synthetic drugs soon replaced the old botanical products for two reasons ${ }^{7}$. In the first place, they were novel chemical entities, subject to patent protection, which allowed them to be sold at a high price to cover the research costs involved in developing them and still enable the manufacturer to earn a sizeable profit. Also, as single 
chemical entities their activity could be easily standardized, and reproducible potency was not a problem.

In comparison, many of the old botanicals were also effective, but they were discarded because of lack of patentability and subsequent assured profit margins. Because they often owed their activity to multiple ingredients, many of which remained unidentified, they were difficult to standardize. Uniformity of action was practically unattainable.

Digitalis (Digitalis purpurea L.) typifies the problem. Valued as a remedy for congestive heart failure, the herb is basically superior to any single glycoside isolated from it because it contains both short-acting and long-acting glycosides of rapid and slow onset. However, the leaf was impossible to standardize with any degree of accuracy. After trying various animals, including guinea pigs, goldfish, chick hearts, frogs, cats, water fleas, and pigeons, with little reproducibility, researchers finally gave up, and digitalis leaf is no longer used in America ${ }^{8}$.

Ultimately, almost all botanical remedies disappeared from the shelves of pharmacies, and by the 1960s the medicines available in the United States, unlike those utilized in most other countries, were almost totally synthetic.

\section{New developments in Europe and the US}

Then a curious thing happened. In the 70s and 80s, scientific and clinical reports began to come out of advanced European countries, especially Germany, indicating that the herbal remedies which had never been totally discarded there, had many substantial therapeutic and economic benefits for the consumer' ${ }^{9}$. It was quite disappointing for some in the USA to learn that a few of the all-American herbs such as echinacea (Echinacea spp.) and saw palmetto [Serenoa repens (Barb.) Small] had been found by European scientists to confer useful, sometimes unique, therapeutic benefits and to do so without causing significant adverse effects. Americans began to demand these products, companies began to supply them, and by the late 1990s annual sales in the USA had reached almost $\$ 4$ billion with demand for some occasionally outdistancing the supply ${ }^{10}$.

\section{Laws and regulations}

But all was not well in herbal America. The Food and Drug Administration (FDA) had long insisted that to obtain approval as a drug in this country, herbs had to be supported by the same amount of costly evidence of efficacy required for new synthetic drugs. Because of lack of patentability of the long-known herbs and consequent lack of market exclusivity, companies were unwilling to make the substantial investment required to prove their efficacy. Consequently, only a handful of herbs, many of them quite insignificant from the therapeutic viewpoint - witch hazel (Hamamelis virginiana L.) water, for example - have ever received drug approval in the USA.

Nevertheless, millions of people continued to use the unapproved products. FDA personnel, accustomed only to dealing with new synthetic, single chemical entities, simply did not know how to react. They attempted to call black currant (Ribes nigrum L.) oil encapsulated in gelatin an unapproved food additive. In the ensuing court case the presiding judge, in ruling against the FDA, characterized the Agency's reasoning as an "Alice-in-Wonderland" approach. He went on to accuse the FDA of trying to make "an end-run around the statutory scheme"11. A prominent European producer of standardized ginkgo (Ginkgo biloba L.) extract applied for drug approval for the product and was told to reapply after identifying and establishing the safety and efficacy of every constituent in the extract.

In the early 1990s, David Kessler, M.D., FDA Commissioner, who was apparently unaware of the European scientific and clinical studies supporting the safety and therapeutic utility of many of the herbal products, began to lash out against them, referring to all those involved in the field as "snake oil salesmen". In stating "It is time to do what needs to be done", his intention to remove all such unapproved herbal products from the US market became obvious $^{12}$

It would have been interesting if he had succeeded. I can imagine, with tongue partially in cheek, our overcrowded courts dealing with cases involving the possession of a clove of garlic (Allium sativum L.) with intent to use as an illicit hypocholesterolaemic drug or of a bottle of prune (Prunus domestica L.) juice purchased for use as an unapproved laxative.

But this was not to be. An infuriated public concerned not only about the loss of their right to purchase herbs, but also vitamins, amino acids and dietary supplements, aided and abetted by commercial interests, struck back hard. Movie stars were enlisted to make TV spots urging the government not to take away their herbs and vitamins. Congress received more communications on the subject than on any public concern since the Vietnamese war. After much wheeling and dealing, the Dietary Supplement Health and Education Act of 1994 (DSHEA) was passed and became law.

\section{Influence of DSHEA}

DSHEA, as it is widely known, was and is a two-edged sword. It kept the herbal products on the market but did not allow therapeutic claims to be made for them. It did permit a nebulous statement on the label regarding the product's effect on the structure or function of the human body, but such generalizations are meaningless to most consumers. It required a follow-up statement indicating the claim had not been evaluated by the FDA, and finally a thoroughly hypocritical statement noting the herb was not 
good for anything; that is, the product was not intended to diagnose, treat, cure or prevent any disease ${ }^{13}$. Of course, that is why the consumer purchased it in the first place, so users disregarded the label and turned to other sources, books, pamphlets, fliers, and the Internet for information. Much of what they found was hyperbolic in character, designed to sell the product, not to inform accurately.

The law also required the appointment of a Presidential Commission on Dietary Supplement Labels to study the matter and make recommendations concerning future actions. The Commission, after meeting over a period of more than 2 years, made an important recommendation that the FDA appoint a panel of independent scientific experts to evaluate the safety and efficacy of herbal products ${ }^{14}$. The Agency did not take up the recommendation, citing a lack of funds to conduct such a study.

Subsequently the FDA, which retained the right to remove from the market any herb shown to be unsafe, made an overture to gain additional authority over such products. It proposed a redefinition of disease, broadening the meaning of that term to such an extent that almost any variation from normal metabolism - sneezing, snoring, constipation, menopausal symptoms, benign prostatic hyperplasia - would be considered a disease $\mathrm{e}^{15}$. Such a redefinition would give the Agency much more control over structure/function claims. The flood of negative comments regarding the proposal was such that it was never implemented.

Instead, early this year the FDA published (65 Fed. Reg. 1000; 6 January 2000) final regulations defining the boundary between structure/function and disease claims. Basically, these liberalized the claims that can be made for the utility of herbal products. Unfortunately, the regulations tend to overlap dietary supplement structure/function claims with over-the-counter (OTC) drug claims. They are therefore quite confusing. They are also internally inconsistent, classifying relief of menopausal hot flashes as a structure/function claim but treatment of the effects of benign prostatic hyperplasia (BPH) as a disease claim. It is my belief that they will do little to meet the public's need for accurate information regarding the efficacy and safety of herbal products.

\section{Failures of DSHEA}

Some things DSHEA did not do are probably even more important than what it did do. It required the FDA to establish standards of good manufacturing practices for herbs, a process still in progress more than 5 years later. But it did not establish standards of quality for individual herbal products. The lack of quality assurance for such products is, without question, the biggest single problem in the entire field today. Repeated studies have shown that the quality of herbal products, even those purported to be standardized on the basis of active or marker compounds, varies enormously ${ }^{16}$. There is absolutely no way that consumers can be assured that what is on the label is actually in the package, other than the reputation of the producer. Unfortunately, the name of the original producer is often not identified on the label by the marketer.

This leaves even knowledgeable consumers absolutely bewildered. Which of the dozen or more echinacea products on the shelf is the best? Should I choose a liquid, a capsule, a tablet, a spray, or some other dosage form? ${ }^{17}$ Agencies such as the United States Pharmacopeia and several others are diligently working to develop standards of quality for herbs, but compliance with any such standards remains strictly voluntary.

\section{Borrowed science}

Another major problem in the field today is best characterized as borrowed science. A few reputable and conscientious herbal companies have invested relatively large sums in pharmacologic and clinical studies to evaluate the efficacy of their products. They have done this in spite of the lack of any substantial advantage this might give them in marketing unpatentable botanicals.

Other companies, utilizing different varieties of plants from different sources, harvested and processed in different ways, and converted into dosage forms using different diluents and excipients, simply lean upon the original science and claim that their products are the same and are similarly safe and effective. This is done without any supporting evidence ${ }^{18}$. Although no official survey has been conducted, it is probably safe to say that somewhere between 80 and $90 \%$ of herb products in the US today are based on borrowed science.

\section{The herb market in the US today}

One further observation of herbal science will bring us up to date. After experiencing a decade or more of unprecedented growth, the market for herbal products in the USA today is decidedly flat. The reasons for this levelling off have been explored in some detail, but two factors stand out $^{19}$. Probably the most important is the plethora of junk products available. The would-be consumer buys one of them - let's say a ginseng (Panax spp.) product from which all the active ginsenosides have been extracted, so the marketer was able to buy and to sell it at bargain prices. After using it for a period of time, the lack of any benefits is obvious, if not the reason for the lack. But the negative experience discourages the consumer, who concludes that all herbs are worthless and never buys any of them again.

Another important reason for the current state of the market is the negative publicity in the popular press concerning adverse effects and particularly interactions with other drugs. (Remember, scientifically herbs are diluted drugs even though legally they are dietary supplements, a food category.) All drugs have side effects and the potential for interacting with other drugs. With 
herbs, because of their dilute nature, these are usually mild in character. But negative stories sell newspapers. So when any negative information about a herb is discovered, no matter whether it is accurate or significant, it gets blown up out of all proportion in the popular press.

An example is appropriate here. An in vitro study conducted last year in California determined that when hamster oocytes were incubated with high concentrations of various herbs, penetration by sperm cells was decreased. This physiologically meaningless experiment, which should never have been published in the first place, was picked up by newspapers and some professional journals alike, which reported that St. John's wort (Hypericum perforatum L.), echinacea [E. purpurea (L.) Moench] and ginkgo caused sterility. Such an assertion has never been verified in small animals or in human beings, but it probably caused many persons to cease using herbal products $^{20}$.

\section{A negative view of the future}

So what about the future of herbal medicine? There are two distinct possibilities, which must be considered carefully. In a provocative article entitled 'What Will Happen to Alternative Medicine?' science writer Leon Jaroff takes a negative point of view ${ }^{21}$. Before considering his comments, let me say that I have always objected to rational phytomedicine being called alternative medicine. Many valuable mainline drugs have been obtained from plants over the years, including digitalis (Digitalis spp.), cinchona (Cinchona spp.), the Pacific yew (Taxus brevifolia Nutt.), ergot (Claviceps purpurea L.), the opium poppy (Papaver somniferum L.), coca (Erythroxylum spp.), rauwolfia (Rauvolfia spp.), and numerous others. Besides, some $80 \%$ of the people in the world turn to herbs as their first line of medical treatment. One might make a good case for synthetic, single chemical entities as being alternative medicines in most countries.

However, herbs seem to be stuck with the 'alternative' designation in the United States, and Jaroff's article features pictures of bottles of herbal remedies, including ginkgo extract, St. John's wort and kava (Piper methysticum Forst. f.). He notes that alternative medicine advocates confidently believe that herbal remedies will "not only flourish in the coming decades but will also take their rightful place alongside vaccines, antibiotics, gene therapy, and other tools of modern medicine". His reaction to this is "Baloney". He continues by noting that any medicine "based on myth, irrationality, and deception will eventually be rejected".

\section{The positive view of the future}

Although Jaroff probably does not realize it, his characterization is simply not applicable to many herbal medicines. Are the 39 controlled clinical studies conducted between
1975 and 1997, which establish the value of ginkgo in treating cognitive deficiencies, myth, irrationality and deception? And how about the 30 controlled clinical trials on St. John's wort's effect on depression conducted during the same period? Do they fall in the same baloney category? $^{22}$ Of course not.

Jaroff and so many others who continually talk about the lack of science supporting rational herbal medicine are really talking about their own lack of knowledge of that science. He concludes that alternative medicine (by his definition that includes herbs) will be consigned in the future to its rightful place, "the dustbin of medical history".

I believe that he and his fellow herbal doomsayers are simply wrong. There are a number of reasons. Almost all of the best-selling herbs in the United States - the top ten constitute more than $50 \%$ of the market - have been adequately studied to ensure their safety and efficacy ${ }^{10}$. Most of them are now available in the form of standardized extracts permitting reproducibility of therapeutic effects. Because of their multiplicity of active constituents they bind to multiple receptor sites in the body, and in total produce a significant beneficial physiological effect with minimum side effects. This is in contrast to large doses of single chemical entities that almost always produce significant side effects.

In addition, many of the herbs have beneficial actions not duplicated by so-called conventional drugs ${ }^{23}$. For example, the immune-stimulating properties of echinacea, the tonic properties of ginseng, and the liver-protective and restorative actions of milk thistle [Silybum marianum (L.) Gaertn.] are not effectively duplicated by synthetic chemicals. Consequently, a number of these effective, safe, relatively inexpensive, standardized herbal products are bound to enter mainstream American medicine as useful drugs just as they already have in several advanced European nations.

\section{Some problems to be solved}

However, before that can take place the attitude of several major factions in the herbal field must be changed ${ }^{24}$. First of these are the uninformed professionals who continually repeat the dictum that there is no evidence to support the efficacy of herbal remedies. I always ask such persons if they have read the English language summaries of the available evidence in the book Rational Phytotherapy. Not surprisingly, I have yet to find one such critic who has studied the evidence provided there.

Then, too, the attitudes of many herbalists must be changed. Anyone in the United States can call himself or herself a herbalist. There is no established educational curriculum and no formal education is required. Many are self-taught or are taught by others who are. Although some are very knowledgeable, many still subscribe to nonscientific dogmas such as the Doctrine of Signatures and plant energies. Some of them tend to decry the use of 
standardized plant extracts based on a belief that there is something magical or even mystical about the whole plant. Such erroneous beliefs must be discarded if herbs are to take their rightful place in our materia medica.

The third group whose activities must be changed are certain manufacturers or producers who entered the field solely for profit and not necessarily to benefit the health of the public. Their hyperbolic advertising of unproven claims, their failure to ensure the quality of their products, and their unwillingness to invest a portion of their substantial profits in research must yield to make way for professional acceptance of herbal medicine.

Changing the attitudes and actions of all three groups will not be easy. At the moment, each of them speaks mainly to themselves. Each holds conferences where other points of view are not only unrepresented but are unwelcome. Education is probably the best way to change this, but that is a slow process.

\section{Need for additional research}

I cannot mention future needs without emphasizing the absolute necessity of additional research in the herbal field. For many years, the research and development (R\&D) expenditures of major pharmaceutical manufacturers have hovered around $15 \%$ of total US sales ${ }^{25}$. Although the total annual investment in this area is dropping as the result of numerous cost-saving measures instituted by newly consolidated companies ${ }^{26}$, the percentage is still very large in comparison with the R\&D investment of producers of herbal products. No authoritative figures are available for the herbal industry, but based on the volume of published results, the average R\&D investment must be far less than $1 \%$ of sales. Some companies invest nothing, even though much needs to be done.

For example, valerian is probably our oldest sleep aid, yet after 2000 years of use, we still do not know the nature of its active principles ${ }^{27}$. How can we standardize a dose of valerian effectively if we are ignorant of the effective constituents?

There is an urgent need to establish suitable procedures for analysing and determining the concentration of active components in herbs. Since many owe their activity to multiple constituents of different chemical types - St. John's wort, chamomile (Matricaria recutita L.) and echinacea are examples - we need to develop and to utilize suitable analytical methodologies to ensure that all of these components are present in requisite amounts.

Probably the greatest research need, and unfortunately the most costly, is the need for clinical trials on a wide variety of herbal products. In conducting these, the precise composition of the dosage form must be established. Many of the studies conducted in the USA cannot be replicated because the clinicians involved, believing that herbs possessed the same uniformity as approved drugs, failed to define adequately the dosage form utilized ${ }^{28}$.
We also urgently need more information on the adverse effects of herbs and their interactions with OTC or prescribed drugs. All too often clinicians have taken the identity of the herb on the label at face value, and as a result, many of the reports in the literature on adverse events are inaccurate. The substitution of Chinese silk vine (Periploca sepium Bunge) for eleuthero [Eleutherococcus senticosus (Rupr. \& Maxim.) Maxim.] is just one example of erroneous reports of side effects and interactions caused by mislabelled herbs ${ }^{29}$.

\section{Need for suitable regulations}

The tasks remaining before us, enumerated above, are not insurmountable. Probably the most difficult task that lies ahead deals with the establishment of suitable regulations that will not only allow herbs to be approved as drugs with appropriate quality standards but will encourage such approvals. Theoretically, the road to drug approval is open, but in actuality it is closed by the amount and the cost of evidence required to prove one of these non-patentable herbs effective. Many cost figures for such proof have been cited, all of them in the hundreds of millions of dollars. Even if only tens or scores of millions are involved, the costs are excessive for products lacking a market exclusive.

Consequently, while scores of Investigational New Drug (IND) applications have been filed on herbs, not one of them has advanced through the New Drug Approval (NDA) process that would formally grant drug approval. Denial of such approval simply denies any need for mandatory quality standards for herbal products and perpetuates the unsatisfactory status quo.

In my opinion, this is a scandalous situation. Here we have products that are used by one-third of the adult population in the United States with a retail annual market value approximating $\$ 4$ billion and the FDA, by establishing artificially high proof-of-efficacy hurdles, refuses them drug approval ${ }^{11}$. Compare this with the situation that has worked so well in Germany for many years in which 'reasonable' amounts of proof are accepted as evidence of the efficacy of phytomedicines, allowing the products to become an integral part of mainstream medicine ${ }^{30}$.

It has long been a mystery to me as to why the FDA refuses to adopt a reasonable approach to herbal medicine. Drug approval would not only give them greater regulatory authority over essentially unregulated commodities but it would also be of immense benefit to the consumer by providing quality assurance for the products. The attitude of the policy makers in the FDA remains, in my opinion, the greatest obstacle to overcome before herbal medicine can become an integral part of so-called conventional medical practice.

\section{Herbal integration promises a bright future}

Even after working in the field of plant drugs for nearly 50 years, I remain an optimist. After all, for much of that 
period natural drug products were scorned by professionals and the public alike. Now they are highly valued, and with good reason, by a very large segment of the population.

There is no question in my mind that herbal medicine will continue to flourish and eventually become integrated into our materia medica. Looking back, it is obvious that a great deal of progress has already been made. We now look to the future with eager anticipation and great expectations.

\section{References}

1 Solecki M. Shanidar: The First Flower People. New York: Alfred A. Knopf, 1971: 245-50.

2 Emboden W. Narcotic Plants. New York: Macmillan Publishing Co., 1979: 50.

3 Booth M. Opium. New York: St. Martin's Press, 1998: 15.

4 Capasso L. 5300 years ago the Ice Man used natural laxatives and antibiotics. Lancet 1998; 352: 1864.

5 Tyler VE, Was Lydia E. Pinkham's Vegetable Compound an effective remedy? Pharm. Hist. 1995; 37: 24-8.

6 Tyler VE. Three proprietaries and their claims as American 'Indian' remedies. Pharm. Hist. 1984; 26: 146-9.

7 Robbers JE, Speedie MK, Tyler VE. Pharmacognosy and Pharmacobiotechnology. Baltimore: Williams \& Wilkins, 1996: $1-14$.

8 Robbers JE, Tyler VE. Tyler's Herbs of Choice. New York: The Haworth Herbal Press, 1999: 3, 128.

9 Schulz V, Hänsel R, Tyler VE. Rational Phytotherapy. Berlin: Springer Verlag, third edition, 1998: 306.

10 Brevoort P. The booming U.S. botanical market: a new overview. HerbalGram 1998; 44: 33-46.

11 Tyler VE. When will there come a savior...? HerbalGram 1997; 41: $27-8,56$.

12 Brimelow P, Spencer L. Just call me 'doc'. Forbes 1993; 152, (12): $108,110$.

13 Israelsen LD. Botanicals: a current regulatory perspective in the United States. In: Lawson LD, Bauer R, eds. Phytomedicines of Europe. Washington, DC: American Chemical Society, 1998: $37-43$.
14 McCaleb R, Blumenthal M. Presidents' Commission on Dietary Supplement Labels Issues Final Report. HerbalGram 1997; 41: 24-6, 57, 64

15 Blumenthal M. FDA proposes new rules on dietary supplement structure-function claims. HerbalGram 1998; 43: 26-8, 57.

16 Tyler VE. The quality of herbal products in the United States today. Healthnotes 1999; 6: 178-81.

17 Brinker F. Variations in effective botanical products. HerbalGram 1999; 46: 33-50.

18 Skinner WJ. Court stops HPF. Nat. Med. Law Newsl. 1999; 3(3): 1,3 .

19 Tyler VE. The herbal market in the United States today. Lloydiana 1999; 4(4): 2-4.

20 Ondrizek RR, Chan PJ, Patton WC, King A. An alternative medicine study of herbal effects on the penetration of zonafree hamster oocytes and the integrity of sperm deoxyribonucleic acid. Fertil. Steril. 1999; 71: 517-22.

21 Jaroff L. What will happen to alternative medicine? Time 1999; 154(11): 77.

22 Schulz V, Hänsel R. Rationale Phytotherapie. Berlin: Springer Verlag, fourth edition, 1999: 380.

23 Tyler VE. An introduction to the medicinal use of botanicals. In: Eskinazi D, ed. Botanical Medicine: Efficacy, Quality Assurance, and Regulation. Larchmont, NY: Mary Ann Liebert, 1999: 13-16.

24 Tyler VE. Recognizing the challenges. In: Fechter S, Wohlmeth H, Waterman P, Perdriau I, Leach D, Body J, Oliver C, eds. Herbal Medicine into the New Millenium. Lismore, Australia: Southern Cross University, 1999: 36-47.

25 Anon. 1989-1991 Annual Survey Report: U.S. Pharmaceutical Industry. Washington, DC: Pharmaceutical Manufacturers Association, 1991: 35.

26 Rose J, Nilsson A. Drug research endures the pain of globalization. Science 1999; 286: 2063.

27 Foster S, Tyler VE. Tyler's Honest Herbal. New York: Haworth Herbal Press, fourth edition,, 1999: 377-9.

28 Tyler VE. Phytomedicines: back to the future. J. Nat. Prod. 1999; 62: 1589-92.

29 Awang DVC. Siberian ginseng toxicity may be case of mistaken identity. Can. Med. Assoc. J. 1996; 155: 1237.

30 Blumenthal M, sr. ed. The Complete German Commission E Monographs. Austin, TX: American Botanical Council/Boston, MA: Integrative Medicine Communications, 1998: 684. 